\title{
Anti Tumoral Properties of Punica granatum (Pomegranate) Seed Extract in Different Human Cancer Cells
}

\author{
Khaled Seidi ${ }^{1,2}$, Rana Jahanban-Esfahlan ${ }^{1,2 *}$, Mozhgan Abasi ${ }^{1}$, Mehran Mesgari \\ Abbasi $^{3}$
}

\begin{abstract}
Background: Punica granatum (PG) has been demonstrated to possess antitumor effects on various types of cancer cells. In this study, we determined antiproliferative properties of a seed extract of PG (PSE) from Iran in different human cancer cells. Materials and Methods: A methanolic extract of pomegranate seeds was prepared. Total phenolic content (TPC) and total flavonoid content (TFC) were assessed by colorimetric assays. Antioxidant activity was determined with reference to DPPH radical scavenging activity. The cytotoxicity of different doses of PSE $(0,5,20,100,250,500,1000 \mu \mathrm{g} / \mathrm{ml})$ was evaluated by MTT assays with A549 (lung non small cell carcinoma), MCF-7 (breast adenocarcinoma), SKOV3 (ovarian cancer cells), and PC-3 (prostate adenocarcinoma) cells. Results: Significant $(\mathbf{P}<0.01)$ or very significant $(\mathrm{P}<0.0001)$ differences were observed in comparison to negative controls at all tested doses $(5-1000 \mu \mathrm{g} / \mathrm{ml})$. In all studied cancer cells, PSE reduced the cell viability to values below $23 \%$, even at the lowest doses. In all cases, IC50 was determined at doses below 5 $\mu \mathrm{g} / \mathrm{ml}$. In this regard, SKOV3 ovarian cancer cells were the most responsive to antiproliferative effects of PSE with a maximum mean growth inhibition of $86.8 \%$ vs. $82.8 \%, 81.4 \%$ and $80.0 \%$ in MCF-7, PC-3 and A549 cells, respectively. Conclusions: Low doses of PSE exert potent antiproliferative effects on different human cancer cells SKOV3 ovarian cancer cells as most and A549 cells ar least responsive regarding cytotoxic effects. However, the mechanisms of action need to be addressed.
\end{abstract}

Keywords: Pomegranate seed extract - A549 - SKOV3 - MCF-7 - PC-3 - cancer cell lines - anti proliferative effects

Asian Pac J Cancer Prev, 17 (3), 1119-1122

\section{Introduction}

The insufficient treatment options for advanced metastatic cancers call for developing efficient methods to take down cancer. One such strategy is through chemoprevention, if possible by the use of non-toxic natural products. (Jahanban-Esfahlan et al., 2010; Valiyari S et al., 2013; Abbasi et al., 2014a; Yousefi et al., 2015). Pomegranate, used for centuries in folk medicine is now being acknowledged as a potential chemopreventive and anticancer agent. The tree/fruit consist of several components as: seed, juice, peel, leaf, flower, bark, and roots, each of which exerts intriguing pharmacologic activity (Modaeinama et al., 2015). The Punica granatum, especially its fruit, possesses a vast ethno medical history and represents a phytochemical reservoir of heuristic medicinal value P. granatum constitute of gallic acid, ellagic acid ,gallocatechins, delphinidin, cyanidin, pelargonidin and sitosterol, which possess potent antioxidant and anti cancer activity. The anticancer activity includes interference with cell proliferation, cell cycle, angiogenesis and invasion (Lansky and Newman, 2007).

Pomegranate seed oil (PSO) comprises $12-20 \%$ of total seed weight. The oil consists of octadecatrienoic fatty acids, with a high content of cis9, trans 11 , cis13 acid (i.e. punicic acid), synthesized in situ from nonconjugated octadecadienoic fatty acid, linoleic acid ,itself about $7 \%$ of PSO. (Singh RP et al., 2002). The fatty acid component of PSO comprises over $95 \%$ of the oil, of which $99 \%$ is triacylglycerols. Minor components of the oil include sterols, steroids, and a key component of mammalian myelin sheaths, cerebroside. Seed matrix includes lignins, fusion products of cell wall components and hydroxycinnamic acids, and potently antioxidant lignin derivatives. Poly phenolic compounds, as well as flavonoids and tannins are abundant in the peels of wild crafted compared to cultivated fruits (Syed et al., 2007).

Previous studies have demonstrated the anticarcinogenic activity of pomegranate extracts in a series of human cancer cells. In this study, we determined to study the cytotoxic properties of seed part of PG (PSE) from Iran on different human cancer cells. 


\section{Materials and Methods}

\section{Preparation of Extracts}

Pomegranate fruit were collected from Mazandaran province, Iran in 2014. The seed parts were separated, dried and grounded into fine powder using a blender. Extractions were performed in a Soxhlet apparatus with methanol. The extract were concentrated by rotary evaporator and then dried in very low pressure. The dried extracts were stored at $-2^{\circ} \mathrm{C}$. A stock of $10 \mathrm{mg}$ of extract was prepared in $1 \mathrm{~mL}$ dimethyl sulfoxide (DMSO) and was filtered using $0.22 \mathrm{~mm}$ syringe filter. The percentage of DMSO in the experiment kept below 0.5).

\section{Determination of total phenolic content (TPC)}

Total phenolic content was determined with FolinCiocalteu Reagent (FCR) according to the a described method (Singleton and Rossi, 1965) with some modifications. Briefly, $0.5 \mathrm{ml}$ of each phenolic extract was mixed with $2 \mathrm{ml}$ of $7.5 \%$ sodium carbonate, and then the mixture was allowed to stand at room temperature for $2 \mathrm{~min}$. After addition of $2.5 \mathrm{ml}$ ten-fold Folin-Ciocalteu reagent, the mixture was incubated in the dark room for $30 \mathrm{~min}$. The absorbance was measured at $720 \mathrm{~nm}$ by using a spectrophotometer. The results were expressed as equivalent $\mathrm{mg}$ of Gallic acid per $100 \mathrm{~g}$ of fresh mass (mg GAE/100 g FM). A standard curve for Gallic acid was plotted under the same conditions as the studied samples. All determinations were performed in triplicates.

\section{Determination of total flavonoid content (TFC)}

Total flavonoid content of the extracts were assayed by the colorimetric method described by other authors (Zhishen et al., 1999; Jahanban- Esfahlan et al., 2012), with minor modifications. CME $(250 \mu \mathrm{l})$ was mixed with $1.25 \mathrm{ml}$ of distilled water and $75 \mu \mathrm{l}$ of a $5 \% \mathrm{NaNO} 2$ solution. After five minutes, $150 \mu \mathrm{l}$ of a $10 \% \mathrm{AlCl} 3$. H2O solution, $500 \mu \mathrm{l}$ of $1 \mathrm{M} \mathrm{NaOH}$ and $275 \mu \mathrm{l}$ of distilled water were added to the mixture. The absorbance of the mixture was measured at $507 \mathrm{~nm}$. The results were expressed as equivalent $\mathrm{mg}$ of Qurcetin per $100 \mathrm{~g}$ of fresh mass (mg Q/100 g FM) and compared with the Qurcetin standard curve, which was made under the same conditions. All determinations were performed in triplicates.

\section{$D P P H$ free radical scavenging activity}

The DPPH radical scavenging activity was determined as described Brand-Williams et al. (Brand-Williams et al., 1995) with some modifications. Various volumes of extracts $(30,50,70$ and $100 \mathrm{~mL})$ were added to $1 \mathrm{~mL}$ of 2,2-diphenyl-1-picrylhydrazyl (DPPH) solution (0.1 mM in methanol) and the reaction mixture shaken vigorously. After incubation at room temperature for $10 \mathrm{~min}$, the absorbance of this solution was determined at $517 \mathrm{~nm}$, by using a spectrophotometer. The antioxidant activity was expressed as IC50 values, which were calculated by nonlinear regression with a one phase exponential association equation using GraphPad Prism version 6.0.

\section{Cell Culture}

SKOV3 (human ovarian carcinoma), MCF-7(human breast adenocarcinoma), PC-3 (Human prostate adenocarcinima), A549 (lung non small cell cancer cells) were obtained from the Pasture Institute (Tehran- Iran). Cells were grown in RPMI 1640 supplemented with 10\% heat-inactivated fetal bovine serum (FBS), penicillin (10 $\mathrm{U} / \mathrm{ml})$, streptomycin $(10 \mu \mathrm{g} / \mathrm{ml})$ and $0.2 \mathrm{mM}$ sodium pyruvate. Cultures were incubated in the presence of $5 \%$ $\mathrm{CO}_{2}$ at $37^{\circ} \mathrm{C}$ and $100 \%$ relative humidified atmosphere.

\section{MTT Assay}

The cells were seeded in 96-well plates with a density of $1 \times 104$ cells/well $/ 200 \mathrm{~mL}$ and incubated for $24 \mathrm{~h}$ at $37 \mathrm{C}$ and $5 \% \mathrm{CO}_{2}$. The cells were treated with different concentrations of solvent extracts $(5,20,100,250,500$, $1000 \mu \mathrm{g} / \mathrm{ml}$ ) and $0.2 \%$ (v/v) DMSO (Merck, Darmstadt, Germany) as a negative control. Paclitaxel (plant-derived chemotherapeutic anti-cancer drug from Taxus brevifolia) was used as a positive control. After $72 \mathrm{~h}$ treatment, 10 $\mathrm{mL}$ of MTT reagent was added to each well. The plates were incubated at $37^{\circ} \mathrm{C}$ and $5 \% \mathrm{CO}_{2}$ for $4 \mathrm{~h}$. Then, 100 $\mathrm{mL}$ of the solubilization solution was added to each well and followed by incubation overnight at $37^{\circ} \mathrm{C}$ to dissolve formazan crystals. Finally, absorbance was read using an ELISA plate reader (Bio Teck, Bad Friedrichshall, Germany) at a wavelength of $570 \mathrm{~nm}$. The percentage of cytotoxicity and cell viability were calculated using following equation: \% Cytotoxicity $=1$-(mean absorbance of treated cells/mean absorbance of negative control) and $\%$ Viability $=100-\%$ Cytotoxicity.

\section{Statistical analysis}

All the data represented in this study are mean \pm SEM of three identical experiments made in three replicate. Statistical significance was determined by analysis of variance, followed by LSD test and p-value $\leq 0.01$ was considered significant. All analyses were conducted using the SPSS 16.

\section{Results and Discussion}

In recent decades, in contrast to all accomplishments in cancer treatment, it still stands out among the most common killers in the world (Jahanban-Esfahlan et al., 2015). According to the 2014 cancer statistics in the United Sates, Among men, cancers of the prostate, lung and bronchus, and colorectum will account for about $50 \%$ of all newly diagnosed cancers ,as prostate cancer alone will account for $27 \%(233,000)$ of incident cases in men. At the other hand, cancers of breast, lung and bronchus, and colorectum, comprises one-half of all cases in women. Breast cancer alone is expected to account for $29 \%(232,670)$ of all new cancers among women. Overall, cancers of the lung and bronchus, prostate, breast, and colorectum continue to be the most common causes of cancer death. These 4 cancers account for almost half of the total cancer deaths among men and women, with more than one-quarter of all cancer deaths due to lung cancer. An urgent need in cancer control today is to develop effective and affordable approaches to the early detection, diagnosis, and treatment of cancer(Siegel et al., 2014).

Among a plethora of options for cancer treatment 
Anti Tumoral Properties of Punica granatum (Pomegranate) Seed Extract in Different Human Cancer Cells

and prevention, natural products especially those rich in antioxidants, have always being regarded as safe chemopreventives to Fight cancer (Abbasi et al., 2014b). Various fractions have been extracted from the pomegranate peel and seeds using ethyl acetate, methanol and water. Extraction with methanol was reported to give a higher yield with greater antioxidant activity and peel exhibited higher activity as compared to seeds, ascribed to its phenolic composition (Singh RP et al., 2002). PSE extract from Persian cultivators showed a high content for divergent polyphenolic and flavonoid compounds ,up to $35.31 \mathrm{mg}$ Q/100g FM (\% TFC) and $371.5 \mathrm{mg} \mathrm{GAE} / 100 \mathrm{~g}$ FM (\% TPC). In agreement with Singh et al findings, our results confirmed that peel extract (PPE) showed significant high amount of TFC (103.61 mg Q/100g FM) and TPC (1532.2 $\mathrm{mg} \mathrm{Q} / 100 \mathrm{~g} \mathrm{FM}$ ) compared to the PSE (data not published). Moreover, DPPH IC50 was determined $52.6 \mu \mathrm{g} / \mathrm{ml}$ for PSE and $1.5 \mu \mathrm{g} / \mathrm{ml}$ for PPE. Surprisingly, cytotoxicity studies reveled that PSE exert superior anti tumoral activity than PPE.

Our results indicated that in all doses, significant or

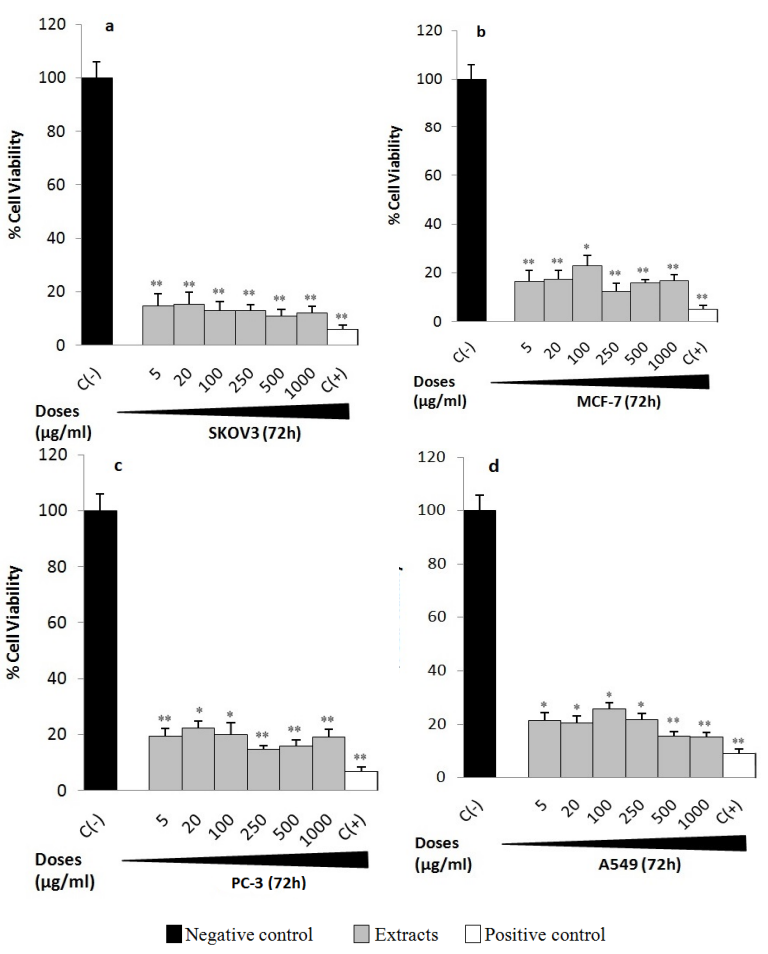

Figure 1. PSE Extract Inhibit Different Human Cancer Cell Proliferation. ${ }^{*} \mathrm{p}<0.01 ;{ }^{*} \mathrm{p}<0.001$, Compared to the Negative Control very significant difference was observed between treated and untreated controls in a dose independent manner (Figure 1, 2). In all cell lines, $5 \mu \mathrm{g} / \mathrm{ml}$ of PSE caused to $\geq 50 \%$ growth inhibition in the treated cells which account for the high toxicity profile of $60 \%$ methanolic extract of PSE (Table1).

In case of ovarian cancer cells, the maximum growth inhibition of $89 \%$ was obtained at doses $500 \mu \mathrm{g} / \mathrm{ml}$, value close to positive control $(20 \mu \mathrm{g} / \mathrm{ml}$ Toxol used as positive control and it caused to $93.76 \%$ growth inhibition of SKOV3 cancer cells) meanwhile dose $5 \mu \mathrm{g} / \mathrm{ml}$ of PSE caused to the lowest growth inhibition of $85.2 \%$. The mean growth inhibition in these cells was $86.61 \%$.

In MCF-7 cancer cells, the maximum growth inhibition of $87.6 \%$ was obtained at doses $250 \mu \mathrm{g} / \mathrm{ml}$, value

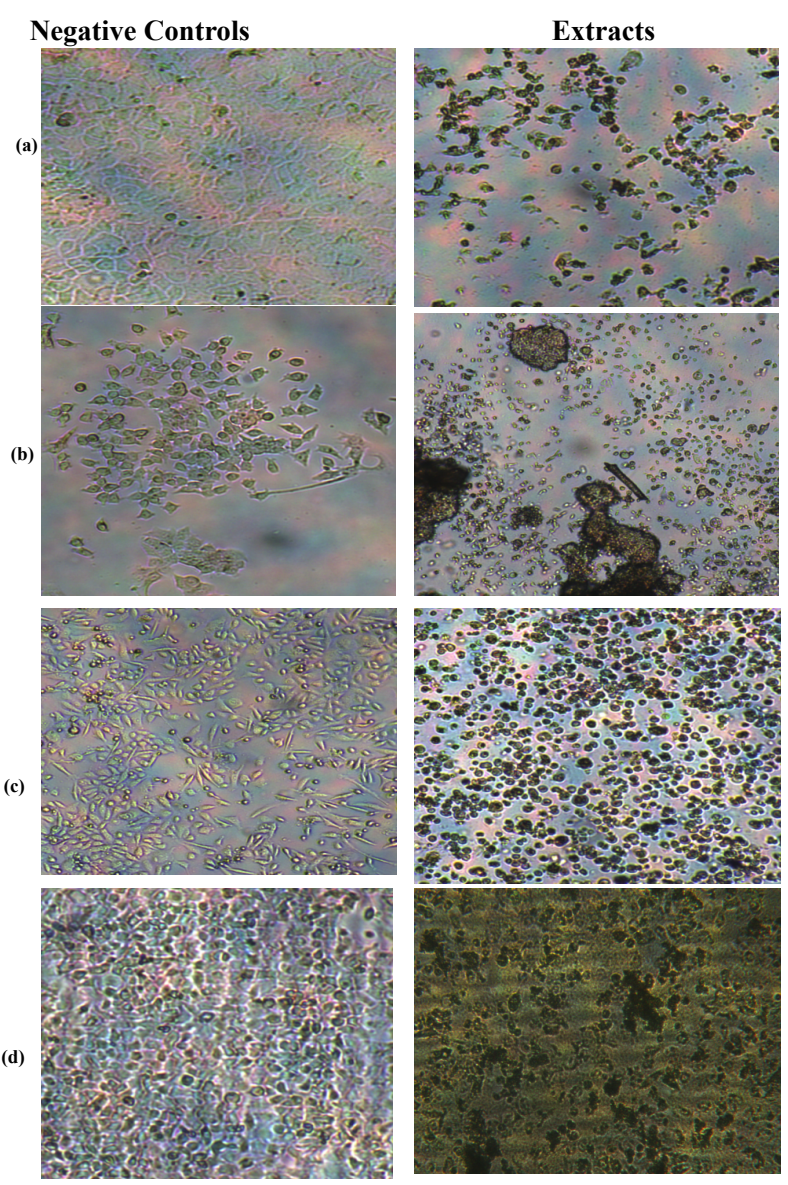

Figure 2. Cytotoxic Effects of PSE on Human SKOV3 (a), MCF-7 (b), PC-3(c) and A549 (d) Cell Lines after 72h Exposure

Table 1. Growth Inhibition \% of Different Doses of PSE on Different Human Cancer Cells

\begin{tabular}{|c|c|c|c|c|}
\hline \multirow[b]{2}{*}{$\begin{array}{c}\text { Doses } \\
(\mu \mathrm{g} / \mathrm{ml})\end{array}$} & \multicolumn{4}{|c|}{$\%$ Growth Inhibition of PSE (72 h) } \\
\hline & SKOV3 & $\mathrm{MCF}-7$ & $\mathrm{PC}-3$ & A549 \\
\hline 1000 & $88.0 \pm 6.2$ & $83.25 \pm 5.4$ & $80.84 \pm 5.5$ & $84.75 \pm 5.1$ \\
\hline 500 & $89.0 \pm 4.0$ & $84.2 \pm 6.6$ & $84.3 \pm 3.9$ & $84.5 \pm 5.3$ \\
\hline 250 & $87.0 \pm 6.4$ & $87.6 \pm 2.4$ & $85.37 \pm 4.4$ & $78.37 \pm 3.9$ \\
\hline 100 & $87.0 \pm 6.1$ & $77.04 \pm 6.1$ & $79.75 \pm 6.1$ & $74.37 \pm 4.8$ \\
\hline 20 & $84.7 \pm 5.2$ & $82.62 \pm 4.4$ & $77.8 \pm 8.2$ & $79.62 \pm 6.7$ \\
\hline 5 & $85.2 \pm 7.8$ & $83.7 \pm 3.2$ & $80.6 \pm 8.1$ & $78.46 \pm 4.4$ \\
\hline Mean \pm SEM & $86.81 \pm 1.2$ & $82.76 \pm 5.6$ & $81.44 \pm 5.5$ & $80.01 \pm 5.8$ \\
\hline
\end{tabular}




\section{Khaled Seidi et al}

comparable to that of $20 \mu \mathrm{g} / \mathrm{ml}$ Toxol which caused to 95.1\% growth inhibition of MCF-7 breast adenocarcinoma cells. The lowest growth inhibition of $77.04 \%$ was obtained at dose $100 \mu \mathrm{g} / \mathrm{ml}$ of PSE. The mean growth inhibition was $82.76 \%$.

In PC-3 prostate adenocarcinoma cells, PSE caused to the maximum growth inhibition of $85.37 \%$ at doses $500 \mu \mathrm{g} / \mathrm{ml}$. In this cell line, $20 \mu \mathrm{g} / \mathrm{ml}$ Toxol caused to $93.1 \%$ growth inhibition of PC-3 cancer cells meanwhile dose $20 \mu \mathrm{g} / \mathrm{ml}$ of PSE caused to the lowest growth inhibition $77.8 \%$. The mean growth inhibition in these cells was $81.4 \%$ (Table1, Figure 2).

In case of A549 cancer cells, the maximum growth inhibition of $84.75 \%$ was obtained at doses $1000 \mu \mathrm{g} / \mathrm{ml}$. Dose $20 \mu \mathrm{g} / \mathrm{ml}$ Toxol caused to $90.25 \%$ growth inhibition of A549 cells. In this cell line, dose $100 \mu \mathrm{g} / \mathrm{ml}$ caused to the lowest growth inhibition of $74.37 \%$. The mean growth inhibition in these cells was $80.01 \%$ (Table1, Fig 2).

In all cancer cells, PSE extract reduced the cell viability to values below $26 \%$, even the lowest doses. In this regard, SKOV3 ovarian cancer cells were the most responsive cells to antiprolifreative effects of PSE with a maximum mean growth inhibition of $86.81 \%$ vs $82.76 \%$, $81.44 \%$ and $80.01 \%$ in MCF-7, PC-3 and A549 cells, respectively. At the other hand, it seemed that lung non small cell cancer cells were the least responsive cells to cytotoxic properties of PSE compared to the other studied cancer cells. This finding could be attributed to the high growth rate of A549 cells in the culture compared to the other studied cells, so higher doses of PSE required to results in the maximum growth inhibition of $\geq 80 \%$.

In a study by Sine Sepehr et al (2012), authors investigated cytotoxic and apoptotic effects of PPE and PSE extract of Iranian Pomegranate on proliferation of PC-3 cells. In this study, PPE caused to the maximum growth inhibition of $65 \%$ at doses $600 \mu \mathrm{g} / \mathrm{ml}$ while PSE caused to no significant growth inhibition on proliferation of PC-3 cells. Pomegranate seed extract (PSE) at the highest dose $(600 \mu \mathrm{g} / \mathrm{ml})$ caused to maximum growth inhibition of $35 \%$. In our experiment, at dose $250 \mu \mathrm{g} / \mathrm{ml}$, PPE and PSE caused to the maximum growth inhibition of $84.16 \%$ and $85.37 \%$, respectively, values comparable to $20 \mu \mathrm{g} / \mathrm{ml}$ Toxol which suppressed $93.1 \%$ growth inhibition of PC-3 cells. These differences could be attributed to the lower antioxidant activity of ethanolic extracts used by these authors, meanwhile the methanolic extract used in our study showed significant content for TFC and TPC and exert a high antioxidant activity. Notably, $1000 \mu \mathrm{g} /$ $\mathrm{ml}$ PSO resulted in lower suppression than $250 \mu \mathrm{g} / \mathrm{ml}$ dose suggesting that an optimal biological dose is more important and relevant than a maximally tolerated one.

In onclusion, low doses of PSE exert potent antiprolifreataive effects on different human cancer cells and it seemed that SKOV3 ovarian cancer cells were the most responsive cells and A549 cells were the least responsive cancer cells to the cytotoxic effects of PSE, however the mechanism of action need to be addressed.
Research Committee(SRC),Tabriz, Iran.

\section{References}

Abbasi MM, Khiavi MM, Monfaredan A, et al (2014a). DOXMTX-NPs augment p53 mRNA expression in OSCC model in rat: effects of IV and oral routes. Asian Pac J Cancer Prev, 15, 8377-82.

Abbasi MM, Monfaredan A, Hamishehkar H, et al (2014b). New formulated "DOX-MTX-loaded nanoparticles" downregulate HER2 gene expression and improve the clinical outcome in OSCCs model in rat: the effect of IV and oral modalities. Asian Pac J Cancer Prev, 15, 9355-60.

Brand-Williams W, Cuvelier M, Berset C (1995). Use of a free radical method to evaluate antioxidant activity. LWT-Food Science Technol, 28, 25-30.

Jahanban- Esfahlan A, Jahanban- Esfahlan R, jamei R, et al (2012). Morphology and physicochemical properties of 40 genotypes of almond (Amygdalus communisL.) fruits. Eur $J$ Experimental Biol, 2, 2456-64

Jahanban- Esfahlan A, Jamei R, Jahanban- Esfahlan R (2010). The importance of almond (Prunus amygdalusL.) and its by-products. Food Chemistry, 120, 349-60.

Jahanban-Esfahlan A, Modaeinama S Fau - Abasi M, Abasi M Fau - Abbasi MM, et al (2015). Anti proliferative properties of melissa officinalis in different human cancer cells. Asian Pac J Cancer Prev, 16, 5703-7.

Lansky EP, Newman RA (2007). Punica granatum(pomegranate) and its potential for prevention and treatment of inflammation and cancer. J Ethnopharmacol, 109, 177-206.

Modaeinama S, Abasi M, Jahanban-Esfahlan R, et al (2015). Anti tumoral properties of punica granatum (pomegranate) peel extract on different human cancer cells. Asian Pac J Cancer Prev, 16, 5697-701.

Siegel R, Ma J, Zou Z, et al (2014). Cancer statistics, 2014. CA Cancer J Clin, 64, 9-29.

Sineh Sepehr K, Baradaran B, Mazandarani M, et al (2012). Studies on the cytotoxic activities of punica granatum 1. var. spinosa (apple punice) extract on prostate cell line by induction of apoptosis. ISRN Pharm, 2012, 547942.

Singh RP, Chidambara Murthy KN, GK J (2002). Studies on the antioxidant activity of pomegranate (Punica granatum) peel and seed extracts using in vitro models. J Agric Food Chem, 50, 81-6.

Singleton V, Rossi JA (1965). Colorimetry of total phenolics with phosphomolybdic-phosphotungstic acid reagents. Am $J$ Enol Viticulture, 16, 144-58.

Syed DN, Afaq F, Mukhtar H (2007). Pomegranate derived products for cancer chemoprevention. Seminars Cancer Biol, 17, 377-85.

Valiyari S, Jahanban-Esfahlan R, Zare Shahneh F, et al (2013). Cytotoxic and apoptotic activity of Scrophularia oxysepala in MCF-7 human breast cancer cells. Toxicological Environmental Chemistry, 95, 1208-20.

Yousefi B, Abasi M Fau - Abbasi MM, Abbasi Mm Fau Jahanban-Esfahlan R, et al (2015). Anti-proliferative properties of cornus mass fruit in different human cancer cells. Asian Pac J Cancer Prev, 16, 5727-31.

Zhishen J, Mengcheng T, Jianming W (1999). The determination of flavonoid contents in mulberry and their scavenging effects on superoxide radicals. Food Chemistry, 64, 555-9.

\section{Acknowledgements}

This study was funded by a grant from Student 